\title{
DO CONCEITO À REALIDADE: A SAÚDE MENTAL DOS CONCLUINTES DE PEDAGOGIA
}

\author{
DEL CONCEPTO A LA REALIDAD: LA SALUD MENTAL DE LOS CONCLUINTES \\ DE PEDAGOGÍA
}

FROM CONCEPT TO REALITY: HEALTH MENTAL OF PEDAGOGY GRADUATES

\author{
Francisco Ednaldo Eufrasio da SILVA ${ }^{1}$ \\ Francisco Ricardo Miranda PINTO ${ }^{2}$ \\ Damares de Oliveira MOREIRA ${ }^{3}$ \\ Stela Lopes SOARES ${ }^{4}$
}

RESUMO: As cobranças exigidas aos acadêmicos concluintes de um curso requerem esforços psicológicos, emocionais e estruturais, além do habitual e por essa razão, os impactos na saúde mental destes, é a temática central deste texto tendo como objetivo compreender as percepções de concluintes do Curso de Pedagogia sobre sua Saúde Mental, no período de finalização do curso. A metodologia utilizada foi de abordagem qualitativa do tipo descritiva e exploratória, tendo como participantes os acadêmicos do $9^{\circ}$ semestre do curso de Pedagogia da Universidade Estadual Vale do Acaraú (UVA), localizada em Sobral-CE, do turno da noite tendo o questionário como protocolo de pesquisa para a coleta de dados. Os dados foram analisados à luz dos autores que tratam da Saúde Mental como Fonaprace (2016). Foi perceptível a dificuldade do estudante em lidar com as emoções na finalização do curso, de forma a interferir em sua saúde mental. Considera-se, por fim, que o acadêmico vive crises em sua Saúde Mental na finalização de sua primeira etapa acadêmica, não tendo, por diversas vezes, o conhecimento desse processo.

PALAVRAS-CHAVE: Saúde mental. Estudante concluinte. Sentimentos.

RESUMEN: las colecciones requeridas para los estudiantes que se gradúan de un curso requieren esfuerzos psicológicos, emocionales y estructurales, además de lo habitual y por esta razón, los impactos sobre la salud mental de estos, es el tema central de este texto con el objetivo de entender Las percepciones de los graduados del curso de pedagogía sobre su salud mental en el período de finalización del curso. La metodología utilizada fue un enfoque cualitativo descriptivo y exploratorio, teniendo como participantes a los estudiantes del $9^{\circ}$

\footnotetext{
${ }^{1}$ Universidade Estadual Vale do Acaraú (UVA), Sobral - CE - Brasil. Graduado em Pedagogia. ORCID: <https://orcid.org/0000-0002-8241-6004>. E-mail: profissionaldoano1910@ hotmail.com

${ }^{2}$ Universidade de Fortaleza (UNIFOR), Fortaleza - CE - Brasil. Doutorando e mestre em Saúde Coletiva. Docente do Curso de Pedagogia da Universidade Estadual Vale do Acaraú (UVA), do Centro Universitário INTA (UNINTA) e do Curso de Direito da Faculdade Alencarina de Sobral (FAL). ORCID: <http://orcid.org/0000-00030771-6266>.E-mail: ricardomiranda195@gmail.com

${ }^{3}$ Universidade Estadual Vale do Acaraú (UVA), Sobral, CE - Brasil. Docente do Curso de Pedagogia. ORCID: <http://orcid.org/0000-0002-9792-6584>.E-mail: damares.abu@ gmail.com

${ }^{4}$ Centro Universitário INTA (UNINTA), Sobral, CE - Brasil. Docente do Curso de Educação Física - EAD e Fisioterapia do UNINTA e da Faculdade Alencarina (FAL). ORCID: <http://orcid.org/0000-0002-5792-4429>. Email: stelalopesoares@ hotmail.com.
} 
semestre del curso pedagógica de la Universidad Estatal Vale do Acaraú (UVA), situado en Sobral-CE, el turno de noche teniendo la Cuestionario como un protocolo de investigación para la recopilación de datos. Los datos fueron analizados a la luz de los autores que se ocupan de la salud mental como Fonaprace (2016). Se percibió las dificultades del estudiante para lidiar con las emociones en la terminación del curso con el fin de interferir en su salud mental. Finalmente, se considera que el erudito experimenta crisis en su salud mental en la finalización de su primera etapa académica, no teniendo, por varias veces, el conocimiento de este proceso.

PALABRAS CLAVE: Salud mental. Estudiante completado. Sentimientos.

ABSTRACT: The collections required for the graduates of a course require psychological, emotional and structural efforts beyond the usual and for this reason the impacts on mental health of these are the central theme of this text aiming to understand the Perceptions of graduates of the pedagogy course on their Mental health in the period of completion of the course. It is important to highlight in the literature the concepts of WHO (2001) as well as the studies already developed by Claudino and Cordeiro (2006). The methodology used was a qualitative, descriptive and exploratory approach having as participants the students of the 9th semester of the pedagogy course of the State University Vale do Acaraú (UVA), located in Sobral-CE, the night shift having the Questionnaire as a research protocol for data collection. The data were analyzed in light of the authors who deal with Mental Health as Fonaprace (2016). It was perceived the difficulties of the student in dealing with emotions in the completion of the course in order to interfere in their mental health. Finally, it is considered that the scholar experiences crises in his Mental health in the completion of his first academic stage, not having, for several times, the knowledge of this process

KEY WORDS: Mental health. Graduate. Feelings.

\section{Introdução}

O estudo da Saúde Mental tem ganhado bastante destaque e a discussão do tema não tem se limitado apenas aos pesquisadores. Os veículos de comunicação em massa têm tratado o tema com bastante destaque devido a importância de debater na atual sociedade que a cada dia tem mostrado uma grande fragilidade emocional.

De acordo com a Organização Mundial da Saúde (OMS), em seu 'Relatório sobre saúde mental no mundo 2001 - Saúde Mental: nova concepção, nova esperança', o número de pessoas que sofrem de perturbações mentais, neurobiológicas ou psicossociais ultrapassa os 400 milhões. No Brasil, 12\% da população, ou seja, 23 milhões de brasileiros necessitam de algum tipo de atendimento em saúde mental (OMS, 2001; BRASIL, 2010).

Os números são impressionantes e demonstram que a saúde mental, no Brasil e no mundo, deve ser tratada com mais atenção pelos órgãos responsáveis pela saúde, pois ela não 
só prejudica o paciente em si, mas todos que se envolvem no processo de recuperação e a sociedade em geral, que muitas vezes é a provocadora das doenças mentais.

Neste contexto, se faz necessário entender dois conceitos importantes. O primeiro é o de saúde, definida pela OMS (1946) como "um estado de completo bem-estar físico, mental e social, não somente a ausência de doença ou enfermidade". O segundo é o de saúde mental que, de acordo a ONU (2016) " "...] trata-se de um estado de bem-estar no qual um indivíduo realiza suas próprias habilidades, pode lidar com as tensões normais da vida, pode trabalhar de forma produtiva e é capaz de fazer contribuições à sua comunidade".

O último período do curso universitário de Pedagogia é um misto de emoções, pois para o estudante é o momento de festejar por estar concluindo uma fase importante de sua vida, por se sentir já habilitado para atuar como pedagogo dentre outros motivos. Entretanto há outros pontos a serem considerados neste período e que podem ser influenciadores do adoecimento mental destes estudantes.

As exigências para o término de curso como o Trabalho de Conclusão de Curso (TCC), as horas de atividades complementares, a carga horária de disciplinas optativas para completar, a tristeza da separação dos amigos que se viam todos os dias durante o período da graduação, além da incerteza de inserção no mercado de trabalho, demandam do estudante um controle emocional e psicológico.

A estimativa é que a cada 3 (três) estudantes universitários 1 (um) apresente algum tipo de doença mental. Destas doenças as mais comuns são os transtornos de ansiedade, depressão, distúrbio do sono e alimentares, síndrome do pânico, estresse, além de somatização de doenças clínicas como a gastrite, dentre outros (CLAUDINO; CORDEIRO, 2006).

Nos últimos períodos os estudantes são mais exigidos que o habitual, pois além dos trabalhos finais existe uma pressão da sociedade e da família para que consiga logo um emprego. O medo do desemprego é um fator que pode causar vários distúrbios, principalmente a ansiedade.

Estas mudanças importantes, pressões, exigências de realizações pessoais e profissionais, cobranças seguidas de tomadas de decisões difíceis e a própria trajetória acadêmica exigem um grande esforço para a adaptação física, mental e até comportamental (ALMEIDA, 2014).

Partindo da suposta hipótese que o desequilíbrio destas emoções pode ser o ponto chave para o surgimento de doenças mentais como a ansiedade, a depressão, transtornos alimentares

5 Disponível em https://nacoesunidas.org/saude-mental-depende-de-bem-estar-físico-e-social-diz-oms-em-diamundial/. Acesso em 29 abril 2019. 
e de sono, fobias entre outras, gerou-se as inquietações base para a pesquisa que é Saber como está a saúde mental dos estudantes concluintes do curso de Pedagogia e como lidam com as emoções geradas no último período?

Diante destas situações, o estudo se torna de fundamental relevância para que seja possível entender por que o estudante universitário se torna suscetível às doenças mentais, possibilitando tomar medidas que auxiliem os alunos neste processo de adoecimento mental.

O estudo tem como objetivo compreender as percepções de concluintes do Curso de Pedagogia sobre sua Saúde Mental no período de finalização do curso.

\section{Metodologia}

Para este estudo foi empreendida uma pesquisa de abordagem qualitativa, do tipo descritivo e exploratório durante os meses de novembro de 2018 a abril de 2019. Este método difere do quantitativo na medida em que não emprega um instrumental estatístico como base na análise de um problema, não pretendendo medir ou numerar categorias (SAMPIERI; COLLADO; LUCIO, 2013).

O espaço geográfico foi a cidade de Sobral, localizada na região norte do estado do Ceará, distante $250 \mathrm{~km}$ de Fortaleza, a capital do estado. Sobral se destaca em vários aspectos, entre eles a educação e a economia, e conta com uma população de mais de 200 mil habitantes. Sobral é conhecida também por ser uma cidade universitária e considerada o maior polo universitário do interior do Ceará, atraindo estudantes de várias cidades da região Norte do estado e de outras cidades mais distantes. A pesquisa ocorreu durante o mês de fevereiro de 2019 tendo como "lócus" a Universidade Estadual Vale do Acaraú - UVA.

O lócus da pesquisa foi o curso de Pedagogia da Universidade Estadual Vale do Acaraú, que fica no Campus Betânia, em um bloco denominado Núcleo de Disciplinas Complementares - NDC. Neste bloco, que foi conquistado depois de muita luta, funciona apenas o curso de Pedagogia, porém ainda existem muitas conquistas a serem concretizadas, como a obtenção de uma sala para o nono período.

Os participantes da pesquisa foram os acadêmicos do $9^{\circ}$ semestre do curso de Pedagogia do turno da noite da Universidade Estadual Vale do Acaraú localizada na cidade de Sobral Ceará. O critério de inclusão foi cursar o nono período e estar matriculado na disciplina de Trabalho de Conclusão de Curso. Já o critério de exclusão foi em relação aos alunos que apenas estão cursando as disciplinas do nono período e os do turno da manhã. 
Para a coleta de dados foi utilizado como protocolo de pesquisa o questionário desenvolvido pelo pesquisador com questões relacionadas as suas experiencias, vivências, emoções e sensações vivenciadas no último período do curso. As primeiras questões dispõem sobre aspectos sociodemográficos dos participantes (como idade, estado civil, cidade em que residem, tempo de deslocamento até a universidade).

A coleta de dados se deu de forma presencial com o público alvo do estudo durante a disciplina de Trabalho de Conclusão de Curso. O professor foi informado sobre a pesquisa que se pretendia fazer com os estudantes e permitiu a aplicação do questionário. O pesquisador foi brevemente apresentado aos estudantes e comentou o conteúdo do questionário. Logo após a apresentação os estudantes ficaram livres para participar do estudo.

Após a coleta dos dados, eles foram devidamente tratados, revisados, avaliados e analisados, utilizando a Análise Temática Categorial de Minayo refletindo de forma temática. Para Minayo (2009) a análise temática busca dar sentido ao que é comunicado da forma como se torna frequente. Os participantes serão chamados pelas siglas ACAD 01, ACAD 02, ACAD 03 em ordem crescente, respeitando os princípios éticos da preservação da identidade presentes na Resolução 510/2016 (BRASIL, 2016).

\section{Resultados e discussão}

Os resultados apresentados se referem aos 42 universitários que compuseram a amostra do estudo, o que representa $95 \%$ do total de acadêmicos matriculados na disciplina de Trabalho de Conclusão de Curso do curso de Pedagogia do turno noturno da UVA, que responderam ao questionário que busca compreender suas percepções e significados da vivência do último semestre do curso a partir de suas respostas ao instrumento de coleta de dados. Vale destacar que 2 (dois) acadêmicos presentes na aplicação do instrumento se recusaram a responder, o que equivale a $5 \%$ do total matriculados na disciplina.

Os participantes têm faixas etárias distintas, sendo que 28 (19\%) destes têm menos de 25 anos, 13 (30\%) participantes têm faixa etária de 25 a 35 anos e apenas $01(5 \%)$ tem entre 36 e 45 anos. Como esperado nos cursos de Pedagogia, a presença feminina é bem maior do que a de homens. Do total dos participantes houve apenas 04 (9\%) do sexo masculino e 38 (91\%) do sexo feminino.

Como a maioria dos estudantes é de fora da cidade sede da universidade, Sobral, sendo estas cidades Massapê, Reriutaba, Forquilha, Ibiapaba, Tianguá entre outras, o tempo de 
deslocamento casa-faculdade varia muito, podendo chegar até 3 horas de viagem. Na população pesquisada $76 \%$ são destas cidades citadas. Em relação ao estado civil dos participantes 31 (73\%) são solteiros, dos quais 4 (9\%) tem filhos. Já dos 11 (26\%) casados apenas $04(10 \%)$ possuem filhos.

Em se tratando da saúde mental dos universitários, um fator que pode ter influência no seu processo de adoecimento é o tempo dedicado para estudar e trabalhar. Trinta e dois dos participantes trabalham o que representa $76 \%$ do total. Vale ressaltar que, desse total, onze são professores. A carga horária de trabalho está entre 4 e 12 horas de trabalho por dia. Em relação aos estudos, $100 \%$ dos entrevistados se dedicam aos estudos, sendo que alguns dedicam mais de quatro horas para a atividade sem intervalo para descanso. Sete participantes não especificaram o tempo dedicado.

Como questionamento constante no protocolo, buscou-se saber qual a concepção de saúde mental que os universitários possuem. Os estudantes veem a saúde mental como o controle das emoções, ou seja, estar bem psicologicamente. Um destaque é que muitos citam a saúde física relacionando-a com a mente. Em suma, de acordo com os entrevistados é o bemestar psicológico, a capacidade de lidar com as emoções e os desafios da vida como relatam os participantes abaixo:

Saúde mental está ligada ao cansaço tanto do cérebro como físico. É uma somatização de fatores. (ACAD 08)

Problemas em relação as emoções. (ACAD 11)

Estar psicologicamente bem, ter controle sobre seus sentimentos. (ACAD 17)

Uma pessoa bem equilibrada que saiba lidar com seus sentimentos, isso se tiver uma boa saúde. (ACAD 22)

É o indivíduo estar de bem com a vida, seja espiritualmente, corpo e mente. Ter qualidade de vida. (ACAD 24)

É a pessoa estar de bem física e psicologicamente, ter qualidade de vida. (ACAD 33)

Este entendimento dos participantes é o que mais se aproxima do conceito contemporâneo de saúde mental que para Teixeira e Pereira (2013) é o "processo resultante da interação entre as várias facetas da existência humana: psíquica, biológica, social, cultural e ambiental".

Três estudantes citaram a família, os amigos, entre outros fatores de convívio social como contribuintes para uma boa saúde mental. 
Estar de bem com a família, amigos, ajudando o próximo assim sendo possível. (ACAD07)

É estar sem problemas com a família, no trabalho, nos estudos, está sem conflitos com os amigos e o próximo. (ACAD40)

Para se ter uma boa saúde mental é você conviver bem com sua família, amigos, sem estresse com os que convive com a pessoa. E sem ter ansiedade. (ACAD42)

Apesar do histórico da saúde mental apontar a família como um dos desencadeadores do adoecimento mental no qual motivava o isolamento do paciente, a família hoje é vista como uma das principais colaboradoras no tratamento dos que sofrem psicologicamente. De fato, a família no contexto da saúde mental, tem uma importância elevada tanto para os agravos em saúde mental, mas também no cuidado de quem sofre de algum tipo de doença mental. A família é lugar de intimidade, construção de sentidos e expressão de sentimentos, onde se exterioriza o sofrimento psíquico que a vida de todos nós põe e repõe (ACOSTA; VITALE, 2008).

Outro ponto a se destacar é que alguns acadêmicos apontam as padronizações da sociedade como provedoras da saúde mental:

Ter a mente saudável. É procurar fazer as coisas da maneira que a sociedade espera. (ACAD14)

Estar ciente de suas funções físicas e mentais agindo de acordo com as boas condutas sociais. (ACAD 19)

Conceituar a saúde mental como um estado de consciência das boas condutas sociais nos remete ao passado, quando a loucura era tida como o desvio das condutas sociais e os indivíduos que fugiam destas condutas eram isolados da sociedade. Porém, ainda na atualidade, não seguir os padrões que a sociedade impõe pode ser um fator crucial para o surgimento das doenças mentais tais como a ansiedade, a fobia social e principalmente a depressão, que pode levar ao suicídio.

A relação saúde/doença mental é a expressão dos estilos de vida e as condições de uma sociedade, advindos de um processo particular para a pessoa. (ADAMOLI; AZEVEDO, 2009). Matos (2004) reafirma, neste sentido, que "novos desafios multifacetados se colocam para a saúde/bem-estar, dentre os quais se destacam os aspectos de pressão social relacionados com o estilo de vida, uma vez que as pessoas são pressionadas a "ter", a "parecer", a esconder sentimentos". 


\section{Turbilhão de sensações}

O último período de um curso universitário é um momento único na vida do estudante, pois é a realização de um sonho, porém as emoções e sentimentos podem gerar uma confusão na cabeça do universitário, pois a aproximação do fim da graduação aumenta as responsabilidades. As emoções e sentimentos são de fundamental importância tanto numa perspectiva social, biológico como também a psicológica (VAZ SERRA, 1999). Ao analisar as falas dos participantes da pesquisa, podemos constatar que os sentimentos de pressão e alívio surgem muitas vezes no mesmo período.

Medos, aflições, angústia, felicidade. (ACAD 03)

Sentimentos de conclusão, alívio. (ACAD10)

Pressão e ao mesmo tempo alívio por estar próximo de concluir. (ACAD21)

Primeiro, felicidade por estar se formando, preocupação por não ter concluído o TCC ainda e saudade da turma e amigos que conquistei. (ACAD22)

É um momento de estresse devido a elaboração do trabalho de conclusão do curso, porém, é uma época de crescimento e aprendizado. (ACAD24)

Cansada; sobrecarregada. Porém feliz por estar acabando. (ACAD36)

Nas falas dos participantes podemos perceber que o término de curso abrange sentimentos positivos e, ao mesmo tempo, negativos, oriundos das cobranças da universidade e também de si mesmo, e este leque de sentimentos podem gerar altos índices de sofrimento psíquico entre os estudantes universitários. Os estudantes universitários têm sido apontados em várias pesquisas como uma população com taxas preocupantes de queixas de sofrimento psíquico e incidência elevada de transtornos mentais (FONAPRACE, 2016).

Neste contexto é importante indicar que os discentes do último período necessitam ser (re)educados emocionalmente, pois o controle de suas emoções é um potencial promotor e interventor de saúde, visto que o descontrole das emoções pode ser um grande influenciador dos processos de adoecimento mental. Desse modo, é necessário compreender que os afetos, as emoções e as relações pessoais influenciam diretamente numa vida saudável.

Apesar de seis entrevistados terem declarado que o último período é um misto de emoções, a maioria citou apenas pensamentos negativos que perpassam por momentos de pressão, desespero, angústia, medo, tristeza e sofrimento. Podemos destacar as falas dos universitários a seguir: 
A pressão gerada nesse período resulta uma sensação de desespero, regada de sentimentos negativos e até mesmo impotência. (ACAD04)

Ansiedade, pressão para entrar no mercado de trabalho, medo, desespero, insuficiência e tristeza. (ACAD07)

Ansiedade, sensação de estar presa em um local sem saída, cansaço. (ACAD13)

Me sinto sufocada, desgastada, me cobro o tempo inteiro, e me sinto fraca. (ACAD17)

Angústia, ansiedade, sono, sensação de incapaz, sensações ruins. (ACAD29)

Medo, tensão, angústia, sofrimento. (ACAD33)

As falas dos universitários são bem claras em relação ao sofrimento que passam os concluintes do curso de Pedagogia. Sentimentos negativos sobre si próprios e seu desempenho e o medo de não concluir são fatores que vão influir no seu desempenho acadêmico. Estes sentimentos negativos não são só atribuídos às cobranças da faculdade, mas também à forte pressão imposta pela sociedade aos estudantes em relação à entrada ao mercado de trabalho após a conclusão do curso. Não concluir o TCC não é o único medo dos universitários concluintes, pois o medo do desemprego também assusta os acadêmicos, afetando seu desempenho na reta final. Essas pressões, cobranças e desafios se refletem muito na saúde mental, psicológica e física dos estudantes.

Numa perspectiva social, as emoções desempenham um papel de especial relevo na motivação humana, podendo influenciar aspectos como a personalidade, as relações sociais, o desempenho profissional, a vida sexual, a ascensão numa carreira ou a própria maneira de viver dos indivíduos (VAZ SERRA, 1999, p.14).

Os sentimentos negativos dos estudantes foram relatados espontaneamente na pergunta “quais os sentimentos e sensações geradas no último período da faculdade?”, porém os relatos de sentimentos negativos não se resumiram a essa pergunta. Ao serem questionados se havia alguma situação que lhes trazia sensações desagraváveis mais pensamentos e sentimentos ruins foram expostos. Dos quarenta e dois participantes apenas dois responderam que não havia situações desagraváveis no último período e três não responderam.

Para os estudantes o TCC ainda é um grande desafio. Antes mesmo de entrar na universidade é possível ouvir que a época mais difícil da graduação é o último semestre por exigir este trabalho. Já existe a crença de que realizá-lo é um processo de grande sofrimento.

Vinte e quatro participantes do estudo citaram-no de alguma forma como a situação mais desagradável do último período. A preocupação com a escrita, as leituras, a dúvida sobre 
ser capaz de fazer, a falta de tempo para se dedicar à produção até o prazo de entrega são algumas situações que os estudantes passam antes de concluir a graduação e que geram ansiedades, estresse, medos e até mesmo frustação e vontade de desistir. Nesse sentido, podemos destacar as seguintes respostas:

Não chega a ser desagradável, mas a insegurança se torna um pouco incomodo e apreensiva, porque é exige algo não comum do cotidiano, formando um possível medo. (ACAD01)

O desempenho no TCC! Exige muito do que eu estava preparada para enfrentar. (ACAD16)

O fato de ser informada do período das apresentações do TCC, porque está próximo e ainda não o conclui, sendo que o tempo é desfavorável. (ACAD27)

A vontade é de desistir e mandar um foda-se bem alto para todo mundo ouvir. (ACAD30)

Tempo corrido, pois afeta a qualidade do TCC. (ACAD36)

Sim. Pois muitas vezes me sinto incapaz, o tempo tem sido o meu maior problema, pois devido ao trabalho não possuo um momento exato para dedicar-me aos estudos. (ACAD37)

O TCC gera estas sensações desagradáveis por exigir, no final do curso, habilidades que talvez não tenham sido adquiridas no decorrer do curso, gerando no acadêmico a desconfiança e a insegurança sua capacidade. A cobrança de si mesmo leva o estudante a um estado de ansiedade, pois sabe que o TCC tem um peso definitivo na sua conclusão de curso.

O professor-orientador, dentro deste contexto, se faz de fundamental importância para ajudar o estudante a controlar suas emoções. Mas o que podemos ver nas respostas de alguns dos participantes é que o orientador deixa a desejar e acaba sendo mais um fator para o estresse e a ansiedade dos estudantes. Destacam-se as seguintes respostas dos participantes:

Quando vou fazer o TCC, sempre sinto muita ansiedade e medo de não está fazendo o trabalho corretamente ou de não dar tempo de terminar no prazo. Nos encontros com a professora sinto muita ansiedade. (ACAD09)

Sim, as orientações, comunicação com alguns professores pois são incompreensíveis. (ACAD21)

O encontro com a orientadora vivo fugindo dela, ela é ótima mais fico insegurança, não tenho mais sono. (ACAD33)

Desenvolver uma parte do TCC e o orientador riscar e mandar refazer. Isso desanima e faz-nos pensar que não somos capazes. (ACAD34) 
O professor deve ter mais do que habilidades técnicas para orientar seus acadêmicos, ele precisa de ter a sensibilidade para lidar com as emoções dos orientandos, pois o TCC é o primeiro grande desafio do acadêmico. É preciso muito mais que gostar do título é preciso uma capacidade acadêmica, técnica e emocional (GUEDES, 2014).

A relação do orientador com o acadêmico deve ser de colaboração, pois os dois estão elaborando o TCC. O que podemos ver é que no lugar do orientador ser um parceiro, aquele que está contribuindo para o crescimento do estudante como pesquisador está apenas para criticar, apontar os erros sem encaminhá-los para o melhor caminho. Estas atitudes podem gerar uma frustação pela pesquisa e pode ser crucial na educação continuada do estudante, pois este pode perder o interesse em uma pós-graduação.

\section{Considerações finais}

A pesquisa consistiu em analisar como os desafios do último período do curso de Pedagogia influenciam na saúde mental dos estudantes. De acordo com as respostas dos estudantes ao questionário fica evidente que as atribuições e obrigações exigem destes um elevado controle emocional.

Conciliar o trabalho, as relações pessoais, as atividades acadêmicas, o trabalho de conclusão de curso e as expectativas pós-universidade pode ser um gatilho para a ansiedade, estresse, fobias, entre outras doenças mentais. A análise realizada nos leva a entender que o sofrimento psíquico é bastante comum entre os estudantes concluintes pois, nesta fase acadêmica, as emoções e sentimentos diversos os distanciam da realidade, os privam do sucesso e de um bom rendimento acadêmico. A mistura de felicidade, ansiedades, tristeza, angústia e alívio são fatores essenciais na qualidade de vida e influenciadores no processo saúde-doença.

AGRADECIMENTOS: A todos os participantes da pesquisa que contribuíram com suas ricas e importantes experiências; a Coordenação do Curso de Pedagogia da Universidade Estadual Vale do Acaraú (UVA) pela anuência de pesquisa.

\section{REFERÊNCIAS}

ALMEIDA, J. S. P. A saúde mental global, a depressão, a ansiedade e os comportamentos de risco nos estudantes do ensino superior: estudo de prevalência e correlação. 2014. 237 f. Tese (Doutorado) - Curso de Medicina, Faculdade de Ciências Medicas, Lisboa, 2014. 
Disponível em https://repositorio.ipcb.pt/bitstream/10400.11/2939/1/tese.pdf. Acessado em: 19 jan. 2019.

ASSIS, C. L.; SILVA, A. P. F.; LOPES, M. S. Sintomas de estresse em concluintes do curso de psicologia de uma faculdade privada do norte do País. TCC (Graduação) - Curso de Psicologia, Instituto Metodista de Ensino Superior, Cacoal - RO, 2013. Disponível em: https://www.metodista.br/revistas/revistasims/index.php/MUD/article/view/3668/3644. Acesso em: 20 jan. 2019.

BRASIL. Transtornos mentais atingem 23 milhões de pessoas no Brasil. Disponível em: http://www.brasil.gov.br/noticias/saude/2010/06/transtornos-mentais-atingem-23-milhoes-depessoas-no-brasil.pdf. Acesso em: 17 fev. 2019.

CLAUDINO, J.; CORDEIRO, R. Níveis de ansiedade e depressão nos alunos do curso de licenciatura em enfermagem. O caso particular dos alunos da Escola Superior de Saúde de Portalegre. In Millenium, n. ${ }^{\circ}$ 32, p. 197-210, 2006.

DANTAS, C. A. S. O acolhimento humanizado em saúde mental. 2015. 40 f. Monografia (Especialização em Saúde Mental, Álcool e Outras Drogas) - Universidade de Brasília, Brasília, 2015. Disponível em:

http://bdm.unb.br/bitstream/10483/11384/1/2015_CharleiadeAbreudaSilvaDantas.pdf. Acesso em: 17 fev. 2019.

DEPIERI, N. B.; CÍCERO, L. R.; GUIZELLINI, V. S.; BIANCHI, R. O. Qualidade do Sono e Sonolência entre Universitários Formandos. 2016. Disponível em:

http://periodicos.uem.br/ojs/index.php/ArqMudi/article/view/32961 Acessado em: 16 mar. 2019.

FONAPRACE. IV pesquisa do perfil socioeconômico e cultural dos estudantes de graduação das instituições federais de ensino superior brasileiras 2014. Uberlândia: FÓRUM NACIONAL DE PRÓ-REITORES DE ASSUNTOS COMUNITÁRIOS E ESTUDANTIS, 2016. Disponível em: http://www.andifes.org.br/wpcontent/uploads/2017/11/Pesquisa-de-Perfil-dos-Graduanso-das-IFES_2014.pdf. Acesso em: 16 fev. 2019.

FUREGATO, A. R. F., SILVA, E. C., CAMPOS, M. C.; CASSIANO, R. P. T. Depressão e autoestima entre acadêmicos de enfermagem. Revista de Psiquiatria Clínica, 33(5), 239244, 2006. Disponível em http://www.scielo.br/scielo.php?pid=S010160832006000500003\&script=sci_abstract\&tlng=pt Acesso em 17 mar 2019.

MENEZES, P. R.; NASCIMENTO, A. F. Epidemiologia da depressão nas diversas fases da vida. Porto Alegre: Artmed; p. 21-6, 2004.

MINAYO, M. C. L. (Org.) Pesquisa social: teoria, método e criatividade. 28. ed Petrópolis: Vozes, 2009.

OMS. Constituição 1946. Disponível em http://www.onuportugal.pt/"oms.doc. Acesso em 23 de maio de 2019. 
ONUBR. Saúde mental depende de bem-estar físico e social, diz OMS em dia mundial. Disponível em: https://nacoesunidas.org/saude-mental-depende-de-bem-estar-fisico-e-socialdiz-oms-em-dia-mundial/. Acesso em: 21 fev. 2019.

OPAS/OMS. Relatório sobre saúde mental no mundo 2001 - Saúde Mental: nova concepção, nova esperança. Genebra: Organização Mundial da Saúde. Disponível em: http://psiquiatriabh.com.br/wp/wp-content/uploads/2015/01/Relatorio-OMS-da-saude-mentalno-mundo-2001. Acesso em: 27 jan. 2019.

SAMPIERI, R. H.; COLLADO, C. F.; LUCIO, M. P. B. Métodos de Pesquisa. 5. ed. Porto Alegre: Penso, 2013.

VAZ SERRA, Adriano. O stress na vida de todos os dias. Coimbra: Gráfica de Coimbra Ltda. 1999.

\section{Como referenciar este artigo}

SILVA, Francisco Ednaldo Eufrasio; PINTO, Francisco Ricardo Miranda; MIRANDA, Damares de Oliveira; SOARES, Stela Lopes. Do conceito à realidade: a saúde mental dos concluintes de pedagogia. Revista on line de Política e Gestão Educacional, Araraquara, v. 23, n. 2, p. 453-465, maio/ago., 2019. E-ISSN:1519-9029. DOI: 10.22633/rpge.v23i2.12652

Submetido em: 10/03/2019

Revisões requeridas: 15/04/2019

Aprovado em: 06/05/2019

Publicado em: 09/06/2019 